\title{
Carlo Pucci, mathematician and citizen
}

\author{
Alessandro Figà Talamanca $\cdot$ Luigi Pepe
}

Published online: 21 February 2015

(C) Centro P.RI.ST.EM, Università Commerciale Luigi Bocconi 2015

\begin{abstract}
Ten year after his death, the work of over 40 years of the Florentine mathematician Carlo Pucci (1925-2003) is presented in a book entitled Carlo Pucci tra scienza e impegno civile. Pucci worked untiringly to promote mathematical research and the culture of democracy in Italy. His intellectual genealogy is related on one hand to the great mathematical school of Enrico Betti, Ulisse Dini and Luigi Bianchi, through his first teacher, Giovanni Sansone; on the other hand it is related to the culture of democracy of the Italian Risorgimento: Pasquale Villari, Gaetano Salvemini and Ernesto Rossi. Pucci was president of the Committee of Mathematics of the Italian National Council for Research, President of the Italian National Institute of Higher Mathematics, President of the Union of Italian Mathematics, and full professor of mathematical analysis at the University of Florence.
\end{abstract}

Keywords Carlo Pucci - Italian mathematics · Consiglio Nazionale delle Ricerche - Unione Matematica Italiana . Istituto Nazionale di Alta Matematica - Rossi-Salvemini Foundation

\footnotetext{
A. Figà Talamanca $(\bowtie)$

Dipartimento di Matematica, Sapienza Università di Roma, Piazzale A. Moro 7, 00186 Rome, Italy

e-mail: sandroft938@gmail.com

L. Pepe

Dipartimento di Matematica e Informatica, Università di Ferrara,

Via Machiavelli 35, 44121 Ferrara, Italy

e-mail: pep@unife.it
}

\section{Carlo Pucci, mathematician and citizen}

Carlo Pucci passed away in Florence on 10 January 2003, in the house where he was born, in Viale Volta 105, following a long illness borne with stoic determination. He remained lucid until his final days, and from his sickbed continued to concern himself with the mathematical community and the conservation of the memoirs of the movement Giustizia e Libertà (Justice and Liberty). The non-religious funeral service was held in the Department of Mathematics of the University of Florence, and he was buried in the Trespiano cemetery, just a short distance from the tomb of the Rosselli brothers. The intellectual genealogy of Pucci is related on one side to the great mathematical school of Enrico Betti, Ulisse Dini and Luigi Bianchi through his first maestro Giovanni Sansone, and on the other side to the democratic culture of the Italian Risorgimento: Pasquale Villari, Gaetano Salvemini and Ernesto Rossi.

Pucci (Fig. 1) was born in Florence on 3 August 1925. He was president of the Committee for Mathematics of the Consiglio Nazionale di Ricerca (CNR, the Italian National Council for Research), president of the Istituto Nazionale di Alta Matematica (INdAM, the Italian National Institute of Higher Mathematics), president of the Unione Matematica Italiana (UMI, the Italian Mathematical Union), and professor of mathematical analysis at the University of Florence. Nephew of Ernesto Rossi and custodian of the archives of Gaetano Salvemini and his uncle, Carlo was appointed secretary of the committee for the publication of their works, and founded, through his personal behest, the Fondazione Ernesto Rossi-Gaetano Salvemini. His work during the period following World War II, as promoter of mathematical research and of new forms for its governance, was of fundamental importance for the development of the mathematical disciplines in Italy. 


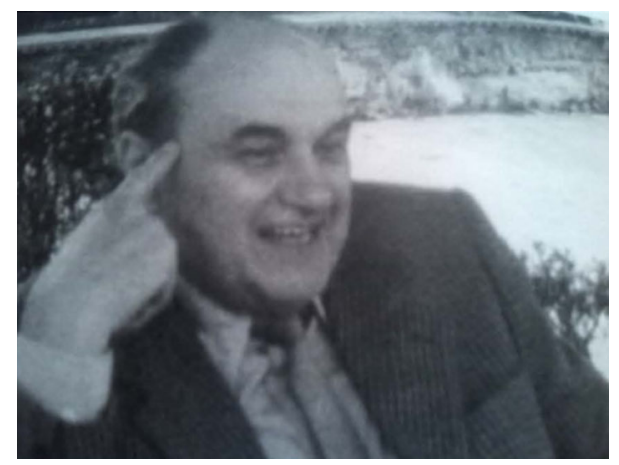

Fig. 1 Carlo Pucci (1925-2003)

To honour the tenth anniversary of his death, a day-long seminar entitled "Carlo Pucci tra scienza e impegno civile", organized by the University of Florence, the Italian Mathematical Union and the Fondazione Ernesto RossiGaetano Salvemini and held in Florence on 24 May 2013, invited reflections on his scientific work and his efforts at organisation over the course of more than 40 years, and his untiring commitment, as a scientist and as a citizen, to the promotion of culture, whose points of reference were the ideals of justice and liberty and the practice of democratic mobilisation. In gathering the papers presented by speakers for publication, we believed it was preferable to follow the chronological order of the periods referred to, so that the result would be a kind of biography of Pucci by many hands. The volume that resulted is Carlo Pucci tra scienza e impegno civile (Fig. 2) edited by Alessandro Figà Talamanca and Luigi Pepe [3].

The volume opens with the lengthy chapter by Antonella Braga that discusses the Pucci family in the 1930s and examines the singular relationship that bound the young Carlo to his maternal uncle Ernesto Rossi, whom he met for the first time in the Roman prison of Regina Coeli, where Ernesto was being held for political reasons. Braga also discusses Carlo's education, his literary tastes, his choice of university studies. At age 18, Carlo had an extraordinary experience with Ernesto, visiting various member of the anti-Fascist movement during the bombing of northern Italy in the summer of 1943. Carlo left several typed memoirs of this experience, which were printed.

This is followed by the recollections of two mathematicians who shared Pucci's Roman sojourn in the 1950s. Edoardo Vesentini presents his valuable testimony of a study program that led to a shared feeling about the necessity of the internationalisation of Italian mathematics, as well as the elaboration of new and more open forms of recruiting researchers and support for research activities. Gianfranco Capriz recalls instead the first developments of electronic calculation in Italy, which saw Carlo and Ernesto "facilitated" by a public investment in the field of new computers with the support of Luigi Einaudi, then President of the

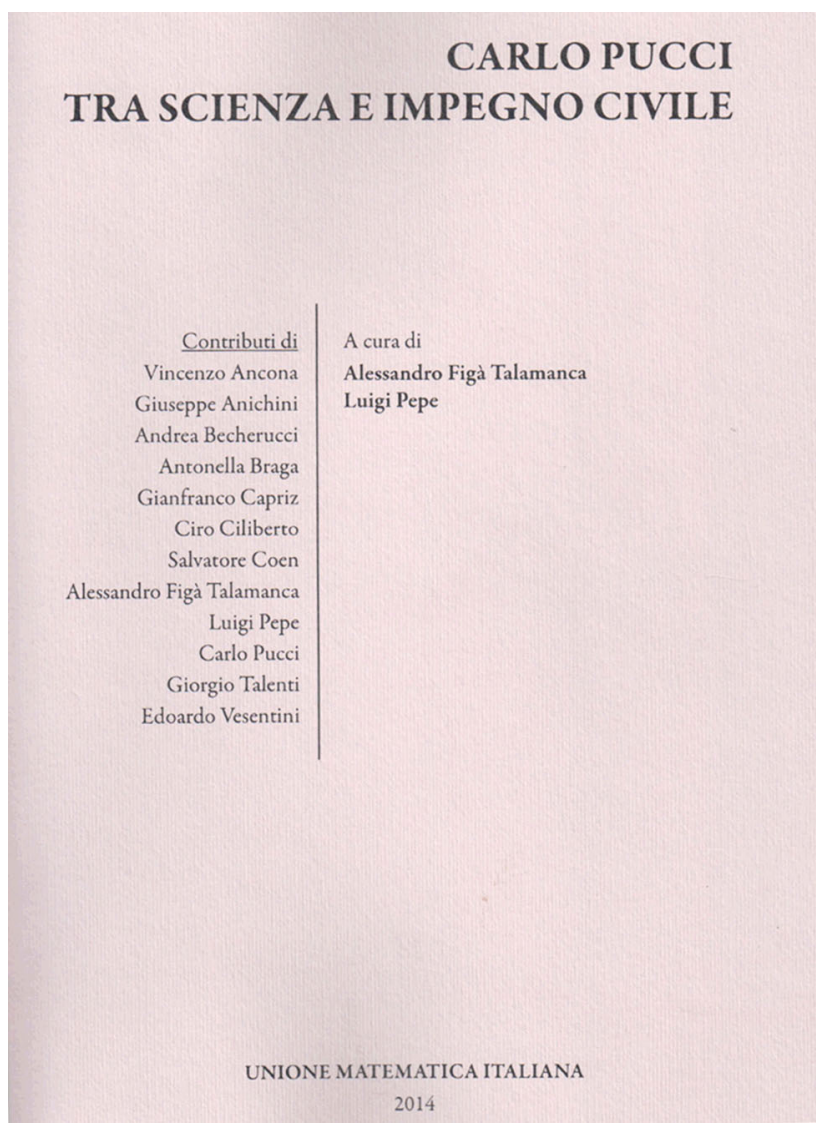

Fig. 2 Cover of the book Carlo Pucci tra scienza e impegno civile

Italian Republic. Next is a collection of letters exchanged between Pucci and Alessandro Figà Talamanca regarding the period of the latter's studies in America and then various university experiences up through the 1980s. This concerns what might be defined for mathematics as "the first brain homecoming", where a period of training abroad is followed by insertion in the Italian university system.

Two contributions, among the most outstanding in the volume, regard Pucci's role in the context of the Committee for Mathematics in the Italian National Council for Research and the Italian Mathematical Union. Alessandro Figà Talamanca presents the legislative framework of the CNR after 1945 and Pucci's work as president of the Committee for Mathematics from 1968 to 1976 . Noteworthy within this context are the training programs for future mathematicians, the inquiries into the new possibilities of use of mathematics in schools, research and industry, the basic national program of study, the summer introductory courses to mathematical research, the strengthening of the lines of study regarding applications within the mathematics degree course, the funding of research and national research groups, the defense of the independence of the scientific community. This is followed by an analysis of Pucci's positions regarding special programs and projects carried out, his disputes with the 
Committee for Physical Sciences, and regarding space research and his fight against the transformation of the CNR into a government-controlled body.

Salvatore Coen's chapter about Pucci and the Union of Italian Mathematicians (UMI) begins with the Naples congress of 1959, during which Pucci, who had then recently returned from a period of research in the United States, was engaged in promoting new forms of organisation of the mathematical community and different and more transparent forms of managing funding for research. Pucci, tenaciously pursuing this strategy, knew how to use on one hand the pre-existing organisation of the UMI, and on the other, and a new form of association: the Associazione Sindacale Ricercatori di Matematica (ASRM), of which he was the heart and soul as well as one of the founders. Naturally he was not alone in this demanding program, and found the consensus on one side from older professors such as Francesco Giacomo Tricomi and Lucio Lombardo Radice, but could count above all on the support of a new generation of mathematicians, including Giovanni Prodi, Enrico Magenes, Guido Stampacchia, Ennio De Giorgi, and others. Thus was born the Collegio Nazionale per la Ricerca Matematica (CONARM), which functioned as a agency for the funding of mathematical research with respect to the CNR and the large public utility, ENI. The role of the CONARM and the ASRM vanished when the Committee for Mathematics of the CNR and the UMI adopted the program as their own. Coen's work then discusses Pucci's role in the Scientific Committee of the UMI and his presidency of that society from 1976 to 1982, concluding with an account of his activities in the UMI, which continued until almost the very end of his days.

A brief chapter by Vincenzo Ancona, president of the INdAM, recounts Pucci's fight for publication of the proceedings and the joint efforts of Pucci and Vesentini to strengthen the institute.

Ciro Ciliberto, current president of the UMI, goes beyond an institutional account and examines two critical phases of the organisation of mathematical research in Italy: 1959, the year that Pucci's program began, and the years of his presidency of the INdAM, marked by conflicts with the new generations of mathematicians.

Luigi Pepe then illustrates the role played by Pucci in the revival of studies in the history of mathematics in Italy. Having attended the lectures of Eugenio Garin and Gaetano Salvemini as a young man, he had an uncommon sense of the importance of the history of science, and as a Florentine he had a genuine fondness for the Italian language in conjunction with the great advances of scientific English. A testimony to this is the beginning of publication, during his presidency of the UMI, of the series Bollettino di storia delle scienze matematiche in 1981; further testimony is the collection of the works of the great mathematicians.
As mentioned, Pucci was the custodian of the archives of Ernesto Rossi and Gaetano Salvemini, which he conserved with care and put at the disposal of scholars. The Salvemini archive is now conserved and catalogued at the Istituto Storico della Resistenza in Toscana, while the Rossi archive is conserved in the Historical Archives of the European Union-HAEU, both in Florence. Both archives are overseen by the Committee for the publication of the works of Gaetano Salvemini and the Fondazione Ernesto Rossi-Gaetano Salvemini.

After his studies in Rome, his period in the United States, and his university teaching in Catania and Genoa, Carlo Pucci returned to Florence, where he had received his degree in 1949. Giuseppe Anichini describes Pucci as a professor in Florence, with particular emphasis on his commitment during the turbulent years of student protests in the Faculty of Architecture. At the time he was almost alone in his opposition the reigning demagogy that voted in favour of cancelling the requirements of the courses of mathematics.

The volume concludes with the essay by Giorgio Talenti, Pucci's first research student in Rome, who remained close to him for the entire arc of his academic career. Talenti provides a portrait of Pucci as a professor and researcher in the celebrated Humboldtian style, which considered good didactics to be inseparable from research activities. During the conference Talenti presented Pucci's book, published posthumously, Istituzioni di analisi superiore [6], as well as the bibliography of Pucci's works, Pubblicazioni matematiche di Carlo Pucci.

While there are by now numerous studies on mathematics and scientific institutes in Italy between the two World Wars, there is still little systematic research on that topic concerning the second half of the century. The most important contributions regarding institutional aspects are $[5,7,8]$. However, this type of work, though indispensable, is often limited to presenting the facts that appear in the official minutes while hardly ever bringing to light the true motivations behind the deliberations. Thus even studies of a biographical nature and the recollections of the protagonists, such as the ones contained in this volume dedicated to Pucci, can make a valuable contribution fo our knowledge of the history of Italian cultural institutions in the field of mathematics in the second half of the twentieth century, where much work remains to be done.

Translated from the Italian by Kim Williams

\section{Appendix: Carlo Pucci Essential Timeline}

\section{5}

3 August: Carlo Pucci is born in Florence, son of Bruno Pucci, retailer, and Clara, the sister of Ernesto Rossi (1897-1967), a historian, economist and militant anti- 
Fascist, student of Gaetano Salvemini. A paternal uncle of Carlo, of the same name, was a professor of zootechnics at the University of Pisa and a socialist member of Parliament. Carlo was the firstborn, and was followed by his sister Fiorella and brother Roberto.

\section{0}

Ernesto is arrested, accused of subversive activity in the movement named Giustizia e Libertà, and condemned the following year to 20 years in prison [1].

\section{7}

Having grown up in an environment of anti-Fascism and veneration of his uncle, Carlo meets him for the first time in the Regina Coeli prison in Rome.

\section{8/1943}

Attends the scientific high school in Florence, where his philosophy teacher is Eugenio Garin.

\section{3}

30 July: Ernesto is released from prison, where he had been placed after a period of confinement in Ventotène. Here, together with Altiero Spinelli, he had prepared the manifesto of the European federalists, entitled Per un'Europa libera ed unita, published clandestinely in 1944 by Eugenio Colorni.

Summer: Accompanies Ernesto on a journey through Northern Italy (Milan, Bergamo, Torino) to meet activists in the movement Giustizia e libertà.

\section{3/1945}

University studies in Florence. Pucci enrols in engineering but leaves his studies to avoid being recruited by the Italian Social Republic (1944), and takes part in the war for liberation in the ranks of the Cremona group, which distinguishes itself in the battle of the Senio. Pucci continues to fight against the Fascist and Germans until the end of the war.

\section{9}

Receives his degree in mathematics in Florence, with Giovanni Sansone as his thesis advisor. Publishes his first work in the Bollettino of the UMI: "Un teorema di derivazione per serie con un'applicazione alle serie trigonometriche" (A theorem of differentiation for series with an application to trigonometric series).

The chair at the University of Florence is restored to Gaetano Salvemini, and Pucci follows some of his lectures with great interest.

\section{0/1951}

Is the recipient of a scholarship at the INdAM, where Mauro Picone introduces him to the study of partial differential equations: from 1951 to 1957 he publishes twenty or so works largely in reference to this field of research.

\section{1}

25-31 October: Attends the 4th congress of the UMI in Taormina.

\section{1/1961}

Assistant to the chair of mathematical analysis at the University of Rome, first of Mauro Picone and then of Aldo Ghizetti. During his stay in Rome he is a frequent guest in the home of Ernesto and Ada Rossi, and visits the Quirinal Palace during the presidency of Luigi Einaudi. As president of the ARAR, and a friend of Einaudi, Ernesto Rossi facilitates the purchase of the first electronic calculators, which are installed in Pisa, Rome and Milan.

\section{4}

2-9 September: Attends the International Congress of Mathematicians in Amsterdam.

\section{6/1968}

Assistant Professor at the Institute for Fluid Dynamics at the University of Maryland (USA). His experience in the United States contribute to broadening his topics of study and scientific collaborations, and allow him to see a new way to organise mathematical research.

\section{7}

6 September: Gaetano Salvemini dies in Capo di Sorrento. His body is moved on 15 October 1961 to the Trespiano cemetery in Florence. The volumes of the Opere di Gaetano Salvemini, compiled by Ernesto Rossi, are published by Feltrinelli between 1961 and 1978. After Rossi's death, Pucci takes his place as correspondent with the publisher.

\section{9}

16 September: In the Assembly during the 6th congress of the UMI in Naples, Enrico Magenes presents a motion, in the name of 43 members, including Pucci, regarding "Mathematical research and its funding", which proposed to strengthen the existing initiatives (CIME, CNR, INdAM) and create new grants and funding for research groups. It also requests the publication of estimated and advisory budgets of various research bodies. The motion is approved by the Assembly. Pucci is also among the signers of a second motion, approved by a large majority, for a "Convention of representatives of the entities and institutes of Italian mathematical research". The organisation is entrusted to a committee composed of Alessandro Faedo, Bruno Finzi, Dario Graffi, Enrico Magenes, Enzo Martinelli, Carlo Pucci, Giovanni Sansone, Beniamino Segre, Guido Stampacchia, Alessandro Terracini and Francesco Tricomi.

\section{0}

27-28 February: The first meeting of the Assemblea dell'Associazione Sindacale Ricercatori di Matematica (ASRM) takes place under the presidency of Lucio Lombardo Radice; the secretary is Francesco Succi, and about 
forty mathematicians take part. The immediate aim of the ASRM is to improve the economic conditions of mathematical researchers and funding on the part of the CNR by means of the creation of research groups. An election by mail of the Executive Committee results in the following: Carlo Pucci, general secretary; Roberto Conti, organising secretary; Domenico Caligo, administrative secretary. Elected members of the council are: Fernando Bertolini, Marco Cugiani, Ennio De Giorgi, Dionisio Gallarati, Luigi Gatteschi, Lucio Lombardo Radice, Enrico Magenes, Aldo Pratelli, Giovanni Prodi and Guido Stampacchia.

28-29 February: The First Convention on the structural problems of Italian mathematics, organised by the UMI. Minister for Public Instruction Giuseppe Medici is present at the inauguration.

14 November: The first Assembly of the Collegio Nazionale per la Ricerca Matematica (CONARM) is held in Pisa. The executive committee is composed of Tricomi (president), Segre (vice-president), Pucci (secretary), Baldassarri, Cafiero, Caligo, Garibaldi, Magenes and Marchionna. The meetings of the ASRM and the CONARM are scheduled to take place one after the other.

\section{1}

The CNR, at the initiative of the CONARM, funds fifty contracts for mathematical research; the research groups are born.

Together with Gabriele Darbo, Pucci wins a competitive examination for the position of full professor of mathematical analysis; at the beginning of the next year he is called to the University of Catania.

\section{1/1967}

During the breaks in his didactic activities in Italy, Pucci is visiting professor at Rice University in Houston (1961, 1963), Louisiana State University in Baton Rouge (1965), and the University of California at Berkeley (1967).

\section{2}

Takes part in the International Congress of Mathematicians in Stockholm.

\section{2/1969}

Full professor of mathematical analysis at the University of Genoa.

\section{2}

31 December: Approval of the reform of middle schools, of a single type, compulsory and free. Pucci takes a stand against the combined courses of mathematics and scientific subjects, citing as justification the scant familiarity of mathematics teachers with the natural sciences. His constant concern is for the improvement of teacher training, to which he devoted various interventions within scientific societies and institutions.

\section{6}

Takes part in the International Congress of Mathematicians in Moscow. Marginal observations on his presentation raised questions of priority with the Russian works of A.D. Alexandrov.

\section{7}

9 February: Ernesto Rossi dies in Rome and Pucci takes over his work of promoting the Opere di Gaetano Salvemini and as curator of his archives.

\section{7/1976}

Member of the Scientific Committee of the UMI.

\section{8/1976}

President of the Committee for Mathematical Sciences of the CNR.

\section{9/1998}

Professor of higher analysis at the University of Florence.

\section{9}

Summer courses in mathematics are begun in Pisa, then moved to Perugia (1971) and Cortona.

\section{9/1972}

President of the Committee of the Electronic Elaborators of the CNR and the Ministry for Public Instruction.

\section{1}

30 January: Guido Stampacchia is replaced by Michele Sce as director of the Istituto per le Applicazioni del Calcolo (IAC). Pucci, who had favoured his nomination, is the principal driving force behind the replacement.

\section{1/1994}

Member of the Board of Associate Editors of the journal Applicable Analysis.

\section{4}

At his impetus, creation of the Notiziario dell'Unione Matematica Italiana, which in the years to follow published news, opinions and comments relating to mathematical research and teaching.

\section{5/1985}

Member of the Editorial Board of the Encyclopedia of Mathematics and its Applications.

\section{6/1982}

President of the UMI, succeeding Enrico Magenes.

\section{6/1979}

Presides over the Educational Committee of the Comitato di Coordinamento delle Associazioni Scientifiche Italiane (COASSI, the committee for the coordination of Italian scientific associations). 


\section{9/1982}

President of the Study Committee for mathematics teaching of the CNR.

\section{9/1987}

President of the COASSI. Some booklets on scientific teaching in different countries are published.

\section{0/1998}

Director of the journal Archimede, dedicated to mathematics teachers.

\section{1/1998}

Directs the Centre (later the Institute) for Global Analysis and Applications (IAGA) of the CNR in Florence.

\section{1}

Founding of the Bollettino di Storia delle Scienze Matematiche. The UMI is the first national scientific society to dedicate a journal to this discipline. Pucci becomes its first managing director, as president of the UMI; Enrico Giusti is named director.

\section{2}

The archives of Gaetano Salvemini, overseen first by Rossi and then by Pucci, are given to the Istituto Storico per la Resistenza in Toscana. Pucci remains secretary of the Committee for the publication of the Opere di Gaetano Salvemini (see http://siusa.archivi.beniculturali.it/cgi-bin/ pagina.pl?TipoPag $=$ comparc $\&$ Chiave $=329050 \&$ RicProgetto $=$ personalita).

\section{$1985 / 1993$}

President of the Istituto Nazionale di Alta Matematica (INdAM).

\section{5/1987}

Director of the strategic project of the CNR entitled Tecnologie ed Innovazioni didattiche (Didactic technologies and innovations).

\section{6}

Publication of Partial Differential Equations and Applications. Collected Papers in Honor of Carlo Pucci [4], which also contains a bibliography of Pucci's mathematical works.

\section{9}

Founds the Fondazione Ernesto Rossi-Gaetano Salvemini of which he becomes the first president. On 7 June 2000 the foundation is elevated to the status of a non-profit organisation by decree of the then President of the Italian Republic Carlo Azelio Ciampi (see http://www.fondazio nerossisalvemini.eu/fondazione.php).

\section{0}

April: Publication of an interview with Carlo Pucci by Salvatore Coen [2].

\section{1}

Deposits the archive of Ernesto Rossi at the Historical Archives of the European Union-HAEU (see: http://www. eui.eu/HAEU/pdfinv/inv-eracs.pdf).

\section{3}

10 January: Dies in Florence, in his family home in Viale Volta 105, following a long illness which nevertheless did not prevent him for taking an interest in the mathematical community and the affairs of Salvemini Archive and the Fondazione Rossi-Salvemini, up to his final days. After a non-religious memorial service held in the Department of Mathematics of the University of Florence, he was buried in the family tomb in the Trespiano cemetery in Florence, where the tombs of Gaetano Salvemini, the Rosselli brothers, Piero Calamandrei and Ernesto Rossi are also found.

\section{5}

August: Publication of Giorgio Talenti's obituary of Pucci [9], containing a bibliography of selected works of Pucci's mathematical publications.

\section{7}

The correspondence of Gaetano Salvemini, conserved in the Archivio dell'Istituto Storico per la Resistenza in Toscana in Florence, is catalogued and microfilmed.

\section{3}

24 May: Ten years after the death of Pucci, a conference in his honour is held in the Aula Magna of the University of Florence, Piazza San Marco 4, Florence. Entitled Carlo Pucci tra scienza e impegno civile, it was attended by more than a hundred scholars from all over Italy.

\section{References}

1. Braga, A., Franzinelli, M.: Ernesto Rossi (1897-1967) Note biografiche. In: Ernesto Rossi. Una vita per la libertà (1897-1967). Bio-bibliografia. Istotuto stori Company della resistenza e della Società Contemporanea nel Novarese e nel Verbano Cusio Ossola "Piero Fornara". http://www.altierospinelli.it/compagni/rossi/ nota_biografica.pdf (2007). Accessed 25 Nov 2014

2. Coen, S.: Ascoltando Carlo Pucci. Domande di Salvatore Coen. Bollettino UMI, La matematica nella società e nella cultura, III-A, 41-56 (2000)

3. Figà Talamanca, A., Pepe, L. (eds.): Carlo Pucci tra scienza e impegno civile. Bologna, Unione Matematica Italiana (2014)

4. Marcellini, P., Talenti, G., Vesentini, E. (eds.): Partial Differential Equations and Applications. Collected Papers in Honor of Carlo Pucci, Lectures Notes in Pure and Applied Mathematics, p. 177, New York, Marcel Dekker (1996)

5. Nastasi, P.: I primi quarant'anni di vita dell'Istituto per le Applicazioni del Calcolo "Mauro Picone", Bollettino dell'Unione Matematica Italiana, serie VIII, vol. IX-A, Dicembre 2006/2 (2006) 
6. Pucci, C.: Istituzioni di analisi superiore. Unione Matematica Italiana, Bologna (2013)

7. Roghi, G.: Materiale per una storia dell'Istituto Nazionale di Alta Matematica dal 1939 al 2003. Bollettino dell'Unione Matematica Italiana, serie VIII, vol. VIII-A, Dicembre 2005/2 (2003)

8. Simili, R., Paoloni, G. (eds.): Per una storia del Consiglio Nazionale delle Ricerche, vol. 2. Bari-Roma, Laterza (2001)

9. Talenti, G.: Necrologio di Carlo Pucci. Bollettino UMI, La matematica nella Società e nella Cultura, VIII-A, 357-377 (2005)

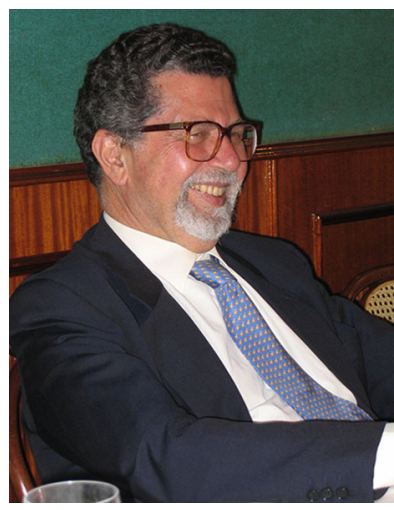

Alessandro Figà Talamanca studied mathematics at the University of Rome and the University of California di Los Angeles (UCLA), where he received his Ph.D. Now retired, he taught for many years at the Universities of Genoa, Perugia and Rome "La Sapienza". He was visiting professor at numerous universities in the United States, including UCLA, MIT, Berkeley and Yale, and in Australia. His research mainly concerned abstract harmonic analysis. He was part of the Italian National Committee of the Mathematical Sciences of the Italian National Research Council, of the National University Council, and the National Council for the Evaluation of the University System. Formerly he served as president of the Union of Italian Mathematics, vice-president of the European Mathematical Society, and president of the National Institute of Higher Mathematics.

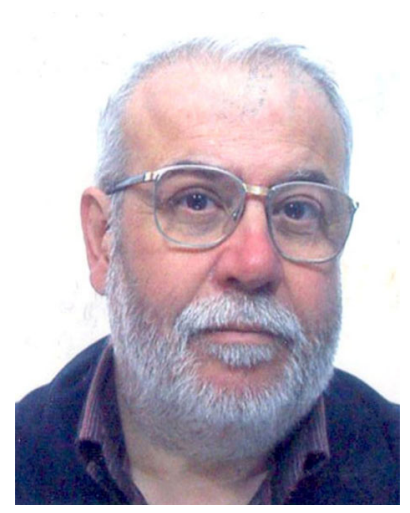

Luigi Pepe is professor at the University of Ferrara. He joins an interest in the history of the mathematical sciences with that of this history of scientific institutions. He is the author of more than 200 publications, including some 20 monographs dedicated to Copernicus, Lagrange, Monge, and the national institutes of Napoleonic Europe. His is the secretary of the committee for the publication of the collected works of Gaetano Salvemini, a corresponding member of the Académie Internationale d'Histoire des Sciences, and president of the Società Italiana di Storia delle Matematiche. 